\title{
Rotraud Von Kulessa, Entre la reconnaissance et l'exclusion. La position de l'autrice dans le champ littéraire en France et en Italie à l'époque 1900
}

\section{Elisa Borghino}

\section{(2) OpenEdition \\ 1 Journals}

\section{Edizione digitale}

URL: https://journals.openedition.org/studifrancesi/4788

DOI: $10.4000 /$ studifrancesi.4788

ISSN: 2421-5856

\section{Editore}

Rosenberg \& Sellier

\section{Edizione cartacea}

Data di pubblicazione: 1 avril 2012

Paginazione: 178

ISSN: 0039-2944

\section{Notizia bibliografica digitale}

Elisa Borghino, «Rotraud Von Kulessa, Entre la reconnaissance et l'exclusion. La position de l'autrice dans le champ littéraire en France et en Italie à l'époque 1900», Studi Francesi [Online], 166 (I | LVI) | 2012, online dal 30 novembre 2015, consultato il 19 novembre 2021. URL: http://journals.openedition.org/ studifrancesi/4788 ; DOI: https://doi.org/10.4000/studifrancesi.4788

Questo documento è stato generato automaticamente il 19 novembre 2021.

\section{cc) (†)}

Studi Francesi è distribuita con Licenza Creative Commons Attribuzione - Non commerciale - Non opere derivate 4.0 Internazionale. 


\title{
Rotraud Von Kulessa, Entre la reconnaissance et l'exclusion. $L a$ position de l'autrice dans le champ littéraire en France et en Italie à l'époque 1900
}

\author{
Elisa Borghino
}

\section{NOTIZIA}

ROTRAUD VON KULESSA, Entre la reconnaissance et l'exclusion. La position de l'autrice dans le champ littéraire en France et en Italie à l'époque 1900, Paris, Champion, 2011, pp. 451.

1 «Un regard dans les histoires de la littérature française et italienne actuelles suffit pour constater l'absence presque totale d'autrices» (p. 9). Comincia così il volume di Rotraud Von Kulessa, docente di letteratura francese, italiana e spagnola presso l'Università di Friburgo, in Germania. Sin dalle prime righe l'accento è messo sulla difficoltà di emergere e di affermarsi per la maggior parte delle scrittrici di tutto il xx secolo, anche a distanza di decenni.

2 Nonostante il Novecento non possa prescindere dall'apporto considerevole della produzione letteraria femminile, $R$. Von Kulessa mette infatti in evidenza come gli unici nomi di donne che compaiono nei manuali di storia letteraria francese siano quelli di Colette, Rachilde e talvolta di Elsa Triolet. La specialista di studi di genere si interroga quindi sulla effettiva fortuna delle duemilacentotrentatré autrici citate da Octave Uzanne nel 1894 e mette alla prova quella che Luigi Capuana definisce nel 1907 come «l'envahissante concurrence des femmes dans la littérature narrative» (p. 313). Una simile affermazione trova forse un perché nell'estrema varietà della produzione letteraria femminile che, inglobando tutti i generi, non si limita solo ai romanzi ma 
include anche un numero considerevole di opere poetiche e teatrali. Un ruolo di primo piano è rivestito inoltre dalla letteratura destinata all'infanzia e all'adolescenza, che conosce in Francia editori di fama come Hetzel e Hachette.

3 Tra le cause di tale diffusione troviamo sicuramente l'imporsi della nuova società borghese che unitamente alla divisione dei compiti all'interno del nucleo famigliare esclude le donne dalla vita pubblica. D'altronde, se l'introduzione della libertà di stampa nel 1881 è una delle condizioni che favoriscono la nascita del movimento femminista, l'esplosione del mercato del libro a partire dal 1880 porta al miglioramento del sistema educativo. Non è un caso Christophe Charle identifichi la letteratura successiva al 1880 come un fenomeno di massa, seppur con diversa portata nei due Paesi: la stampa e l'editoria rimangono i luoghi di espressione privilegiati dalle scrittrici del xx secolo, ma l'Italia risente delle particolarità regionali e si afferma in notevole ritardo rispetto alla Francia.

4 L'intelligenza e la lungimiranza di Kulessa si uniscono per spiegare con un linguaggio semplice ed accattivante come, in un Novecento segnato da profondi cambiamenti sociali ed ideologici - in particolare per quel che riguarda la posizione della donna nella società - la formazione delle identità nazionali tanto in Francia quanto in Italia rivesta un ruolo di primo piano e si rifletta nell'arduo percorso di ricerca identitaria compiuto dalle autrici studiate. Il tutto affinché, pagina dopo pagina, il lettore possa approfondire le proprie conoscenze riguardo ai meccanismi di funzionamento del canone, sulla falsariga delle teorie dei campi letterari di Pierre Bourdieu, senza dimenticare la definizione del concetto di autrice in ambito italiano e francese. 